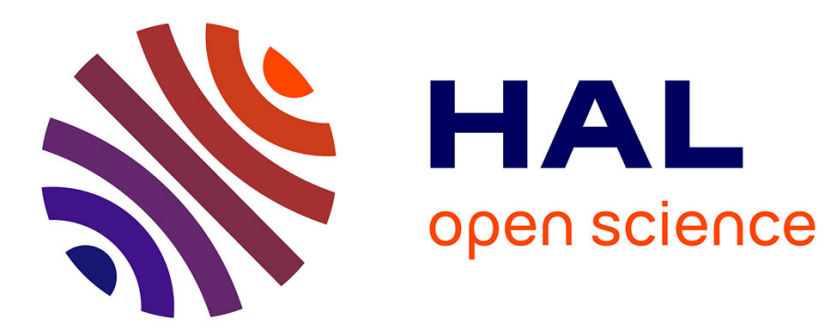

\title{
Viscoelastic properties of wood materials characterized by nanoindentation experiments
}

\author{
Tian Zhang, Shu-Lin Bai, Fei Zhang Yang, Bernard Thibaut
}

\section{To cite this version:}

Tian Zhang, Shu-Lin Bai, Fei Zhang Yang, Bernard Thibaut. Viscoelastic properties of wood materials characterized by nanoindentation experiments. Wood Science and Technology, 2011, 46 (5), pp.10031016. 10.1007/s00226-011-0458-3 . hal-00856969

\section{HAL Id: hal-00856969 \\ https://hal.science/hal-00856969}

Submitted on 25 May 2016

HAL is a multi-disciplinary open access archive for the deposit and dissemination of scientific research documents, whether they are published or not. The documents may come from teaching and research institutions in France or abroad, or from public or private research centers.
L'archive ouverte pluridisciplinaire HAL, est destinée au dépôt et à la diffusion de documents scientifiques de niveau recherche, publiés ou non, émanant des établissements d'enseignement et de recherche français ou étrangers, des laboratoires publics ou privés. 


\title{
Viscoelastic properties of wood materials characterized by nanoindentation experiments
}

\author{
Tian Zhang $\cdot$ Shu Lin Bai $\cdot$ Yang Fei Zhang • \\ Bernard Thibaut
}

\begin{abstract}
The viscoelastic properties of the cell wall of the tropic hardwood Carapa procera are investigated by means of nanoindentation tests. Three types of nanoindentation tests are undertaken: creep, continuous stiffness measurement (CSM) and nanoscale dynamic mechanical analysis (Nano-DMA), corresponding to the increased loading rate and so the response of wood cell wall to the loading in a relatively large time scale. It is found that the creep rate is dependent on the applied stress and the relation can be described by the rule of power law. Regarding the dynamic properties (i.e., storage modulus and damping coefficient) in the frequency range of 10-240 Hz, it is shown that the storage modulus increases monotonically, while the damping coefficient decreases. By using the traditional dynamic mechanical thermal analysis as a reference method, the phase transition behavior of wood cell wall can be successfully characterized by the Nano-DMA in a large frequency scale. A dependence of the storage modulus and damping coefficient on the penetration depth is quantified by the CSM tests.
\end{abstract}

\section{Introduction}

The knowledge of mechanical properties of wood fibers is useful in understanding the macro-behavior of wood materials. Furthermore, the emerging area of natural fiber reinforced composites requires detailed information on the microscale properties of wood fibers (Saheb and Jog 1999).

T. Zhang · S. L. Bai $(\bowtie) \cdot$ Y. F. Zhang

Department of Materials Science and Engineering, College of Engineering,

Peking University, 100871 Beijing, China

e-mail: slbai@pku.edu.cn

\section{B. Thibaut}

Laboratoire de Mécanique et Génie Civil (LMGC), Université Montpellier 2, CNRS UMR-5508, CC 048-Place Eugène Bataillon, 34095 Montpellier Cedex 5, France 
Nanoindentation technology has been proved to be an effective method in detecting material surface properties (Oliver and Pharr 1992; VanLandingham et al. 2001) and has found its application feasibility to natural materials (Isaksson et al. 2010). This method is achieved by monitoring a probe penetrating into the sample surface and recording synchronously the penetration depth and load. The material properties can be extracted by analyzing these data using certain methods. The utilization of nanoindentation technology on measuring wood cell walls is theoretically valid, since the indenter probe has a dimension of $50 \mathrm{~nm}$ in radius (in the case of a Berkovich indenter) and produces an indent area with a diameter of up to 1 or $2 \mu \mathrm{m}$, which is in the same order as the wood cell wall thickness (normally 5-15 $\mu \mathrm{m}$ ). Wimmer et al. (1997) measured the elastic modulus and hardness of spruce wood in the longitudinal direction. Gindl et al. (2004) studied the influence of structural variability (which indicates the factors of MFA and lignin content) on Norway spruce wood cell wall properties by measuring nanoindentation elastic modulus and hardness. It was found that the elastic modulus of the cell wall decreased significantly with increasing MFA, while the hardness showed no statistically significant relationship with MFA and lignin content. Tze et al. (2007) studied the size effect and found an increasing trend of elastic modulus with penetration depth by using portion unloading method. So far, the properties obtained from wood cell walls by nanoindentation technology are mostly elastic properties. However, wood, by its nature, is a viscoelastic material, whose behaviors are sensitive to testing time, frequency, environmental temperature and humidity and have rarely been investigated yet (Lee et al. 2006).

In this study, the viscoelastic properties of heartwood from a Carapa procera tree are studied by nanoindentation tests under loading schemes from static to dynamic procedures. Theoretical analysis and descriptions of the behavior are undertaken to fully understand the viscoelastic properties of woods.

\section{Materials and methods}

\section{Sample preparation}

The species chosen for this study is Carapa procera (abbreviated Cp), which is widely used in South America for cabinetwork. This wood shows an obvious viscoelastic behavior. Small wood pieces from the heartwood were dehydrated with a graded concentration of acetone solutions (70, 80, 90 and 100\%) and then immersed into liquid epoxy resin, followed by the procedure of curing under vacuum for $24 \mathrm{~h}$. To obtain a smooth experimental surface, the resin-embedded samples were sectioned using a Reichert-Ultramicrotome equipped with a diamond knife. The surface was later examined by environmental scanning electron microscope (ESEM), as shown in Fig. 1.

It is shown that the lumina of wood cell walls were filled adequately by resin. This would protect the cell walls from bulking and being destroyed during indentation tests. The cell walls, as shown in Fig. 1, show a large diversity in their shapes and thicknesses. The intrinsic properties, such as MFA, vary even inside a 


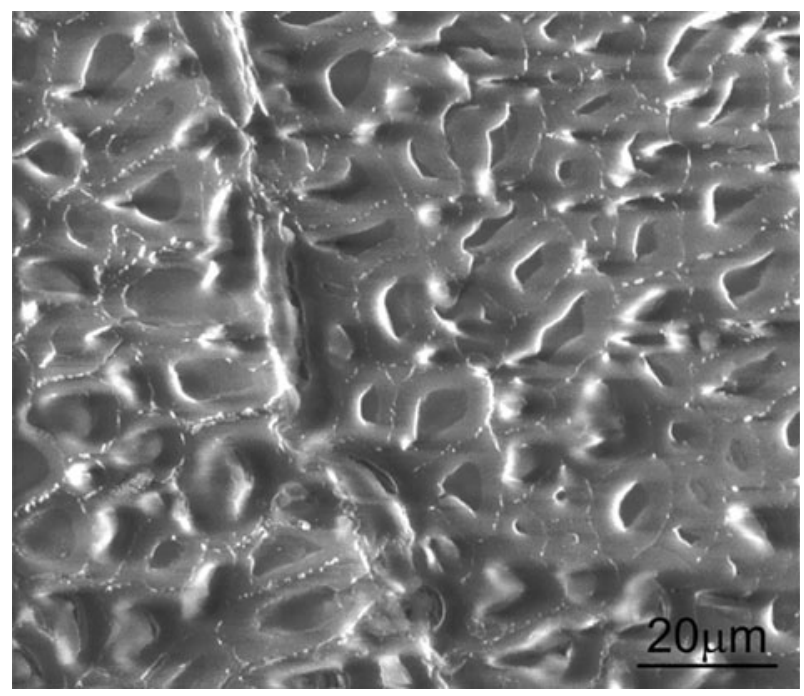

Fig. 1 ESEM micrographs of experimental surface of Carapa procera wood sample used in nanoindentation test

single cell wall (Konnerth et al. 2009). The heterogeneous nature of wood will certainly bring measurement scattering. Therefore, all the indentation tests were performed in an area of $2 \mathrm{~mm}^{2}$ to restrict the influence of structural variations.

Methods and analysis theories

Nanoindentation technique cannot only measure the elastic/plastic surface behaviors of hard materials, such as metal and ceramics (Oliver and Pharr 1992), but also characterize the time-dependent properties of polymers (Cheng et al. 2000; VanLandingham et al. 2001). Regarding the testing time scales, two approaches normally adopted are creep (Lu et al. 2003; VanLandingham et al. 2005; Tweedie and Van Vliet 2006) and dynamic test (Asif et al. 1999; White et al. 2005).

\section{Creep tests}

The material resistance to imposed load can be experimentally evaluated by creep test. In the nanoindentation creep test of this study, the probe indented into the material surface at a large rate $(10,000 \mu \mathrm{N} / \mathrm{sec})$ to reach the prescribed creep load $P_{\max }$, followed by a holding stage of $30 \mathrm{~s}$. The entire experiments were conducted using a Hysitron Triboindenter with a conical diamond tip that has a nominal tip radius of $1 \mu \mathrm{m}$ and a half-apex angle of $60^{\circ}$, at room temperature and controlled relative humidity. In order to detect the load dependence of creep behavior, a series of load levels are adopted from 500 to $1,000 \mu \mathrm{N}$ with an increment of $100 \mu \mathrm{N}$. For each creep load, at least five positions were tested to obtain an average value. For the purpose of validation, the shapes and positions of the residual indentation marks 
were examined immediately after each test by in situ scanning technique, and an average diameter of 2-3 $\mu \mathrm{m}$ was observed.

For a viscoelastic body, the penetration depth increases gradually during the holding stage. For a conical indenter with the half-apex angle $\beta$, the time-dependent depth $h(t)$ produced by a prescribed load $P(t)$ conforms to the following formula (Lu et al. 2003),

$$
h^{2}(t)=\frac{\pi \tan \beta}{2} \int_{0}^{t} J(t-\tau) \dot{P}(\tau) d \tau
$$

where $J=\left(1-v^{2}\right) / E$ is the combined compliance, with $E$ the Young's modulus and $v$ the Poisson ratio. In the indentation creep test, the loading function takes the form of $P(\tau)=P_{\max } H(\tau)$, where $H(\tau)$ is the Heaviside step function. Substitution into Eq. 1 leads to the creep compliance function as,

$$
J(t)=\frac{2 h^{2}(t)}{\pi \tan \beta P_{\max }}
$$

The relative creep compliance is calculated as (Guitard 1983),

$$
J_{r}(t)=\frac{J(t)-J_{0}}{J_{0}}
$$

where $J_{0}$ is the instantaneous compliance.

\section{Dynamic tests}

The dynamic properties, represented by storage modulus, loss modulus and damping coefficient, characterize the material behavior under dynamic loading. The measurement of the dynamic properties is realized by the force modulation method (Asif et al. 1999). An oscillated load (AC load) is superposed on a static load (DC load), $P(t)=P_{D C}+P_{0} \sin (\omega t)$, and the resulting penetration depth takes the form of $h(t)=h_{D C}+h_{0} \sin (\omega t+\varphi)$, where the oscillation part has the same frequency as the AC load but with a phase lag caused by damping of the testing system as well as the contact surface between indenter and tested sample. The global dynamic response (i.e., combined response of the system and the contact surface) can be simulated by a mechanical analog model shown in Fig. 2.

Fig. 2 Schematic of the dynamic model of indentation system in contact with the specimen (Asif et al. 1999)

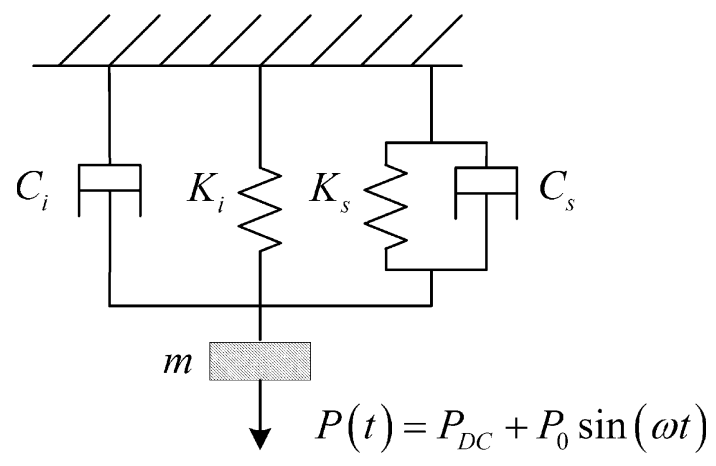


Here, $m$ is the mass of indenter, $\omega$ is the oscillating angular frequency, $C_{i}$ and $C_{s}$ are the damping coefficients of the capacitive displacement sensor and the contact surface, $K_{i}$ and $K_{s}$ are the stiffness of the spring holding the indenter and the contact surface, respectively. Therefore, the amplitude of the oscillated penetration depth can be calculated as

$$
h_{0}=\frac{P_{0}}{\sqrt{\left(K_{i}+K_{s}-m \omega^{2}\right)^{2}+\left[\left(C_{i}+C_{s}\right) \omega\right]^{2}}}
$$

The phase lag between load and depth is

$$
\tan \varphi=\frac{\left(C_{i}+C_{s}\right) \omega}{K_{i}+K_{s}-m \omega^{2}}
$$

$m, C_{i}$ and $K_{i}$ are provided by the calibration procedure through vibrating the indenter in ambient air without touching the sample surface. Then, the dynamic properties (i.e., reduced storage modulus $E_{r}{ }^{\prime}$, reduced loss modulus $E_{r}^{\prime \prime}$ and damping coefficient $\tan \delta$ ) are calculated by

$$
E_{r}^{\prime}=\frac{K_{s} \sqrt{\pi}}{2 \sqrt{A_{c}}}, E_{r}^{\prime \prime}=\frac{\omega C_{s} \sqrt{\pi}}{2 \sqrt{A_{c}}}, \tan \delta=\frac{E_{r}^{\prime \prime}}{E_{r}^{\prime}}=\frac{\omega C_{s}}{K_{s}}
$$

where $A_{c}$ is the contact area between the nanoindenter tip and the penetrated material, determined from the known tip geometry and area calibration procedure.

Based on the force modulation method, CSM and Nano-DMA are carried out to test the sensitivity of wood cell walls' dynamic properties against the static load and angular frequency, respectively. The measurements were conducted using a Hysitron Triboindenter equipped with a three-sided Berkovich diamond tip with a nominal tip radius of $50 \mathrm{~nm}$. The load function of CSM is shown in Fig. 3a, where the static load increased from 10 to $1,000 \mu \mathrm{N}$ at a step of $10 \mu \mathrm{N}$. At each load step, the probe was monitored to oscillate at an amplitude of $10 \%$ of the corresponding static load and a frequency of $10 \mathrm{~Hz}$. The load function of Nano-DMA, as shown in Fig. 3b, uses a static load of $500 \mu \mathrm{N}$ with the oscillation load of $10 \%$ of the static load. The frequency of the oscillation load increases monotonically from 10 to $240 \mathrm{~Hz}$ with $10 \mathrm{~Hz}$ increment and 100 cycles for each cyclic period. For each method, considering the relatively large measurement error of dynamic test, 50 positions were tested.

\section{Results and discussion}

\section{Creep properties}

The variation in penetration depth with time under each creep load is shown in Fig. 4, and the error bar indicates the standard deviation. The penetration depth covers a range from 300 to over $600 \mathrm{~nm}$. This depth is considered to be appropriate to overcome the surface roughness that would bring measurement error and 
Fig. 3 Load functions of dynamic tests: a CSM and b Nano-DMA
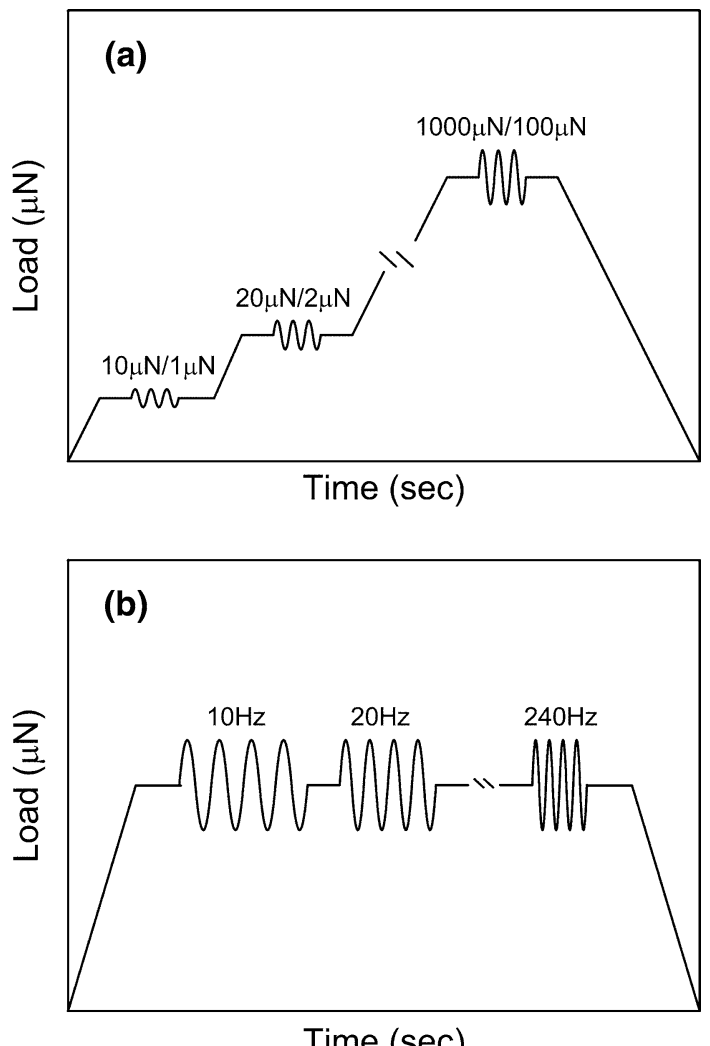

meanwhile not to destroy cell wall integrity. Furthermore, the average values of each load are distinguishable providing a valid ground for the following discussion.

The relative creep compliance calculated following Eq. 3 is shown in Fig. 5a. It is found that the relative compliances are dependent on the stress level. This is obvious by plotting the relative compliance with respect to applied stress (load

Fig. 4 Penetration depths with respect to time under varied creep loads

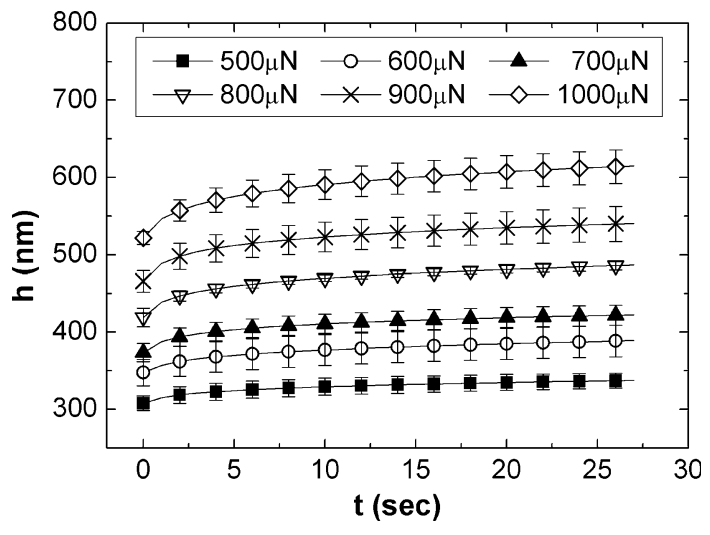


divided by initial contact area) (Fig. 5b). This stress-dependent relation indicates that the behavior of nanoindentation creep is beyond the range of linear viscoelasticity, where the strain increases proportionally with stress and the compliance is independent of stress. Nonlinearity would arise while the applied stress exceeds a critical level (Liu 1993), the value of which varies from wood species, loading mode and environmental factors, such as temperature and humidity. In nanoindentation creep test, the stress level is normally far beyond the proportional limit. Furthermore, in a nanoindentation creep test, the imposed stress introduces a complex stress field where compression and shearing are involved. Stress concentration would also occur at the tip of the indenter depending on the geometry of the indenter. These factors may probably result in a nonlinear behavior in the wood surface. From Fig. 5b, it is found that the relative compliance increases moderately with elevated stress except an abrupt increase at about $370 \mathrm{MPa}$, indicating a creep acceleration stage at larger stress.

The stress-dependent behavior can be represented by a power law relation (Bower et al. 1993),

$$
\dot{\varepsilon}(t)=A \sigma^{n}
$$

Fig. 5 Relative creep compliance with respect to a time and $\mathbf{b}$ stress
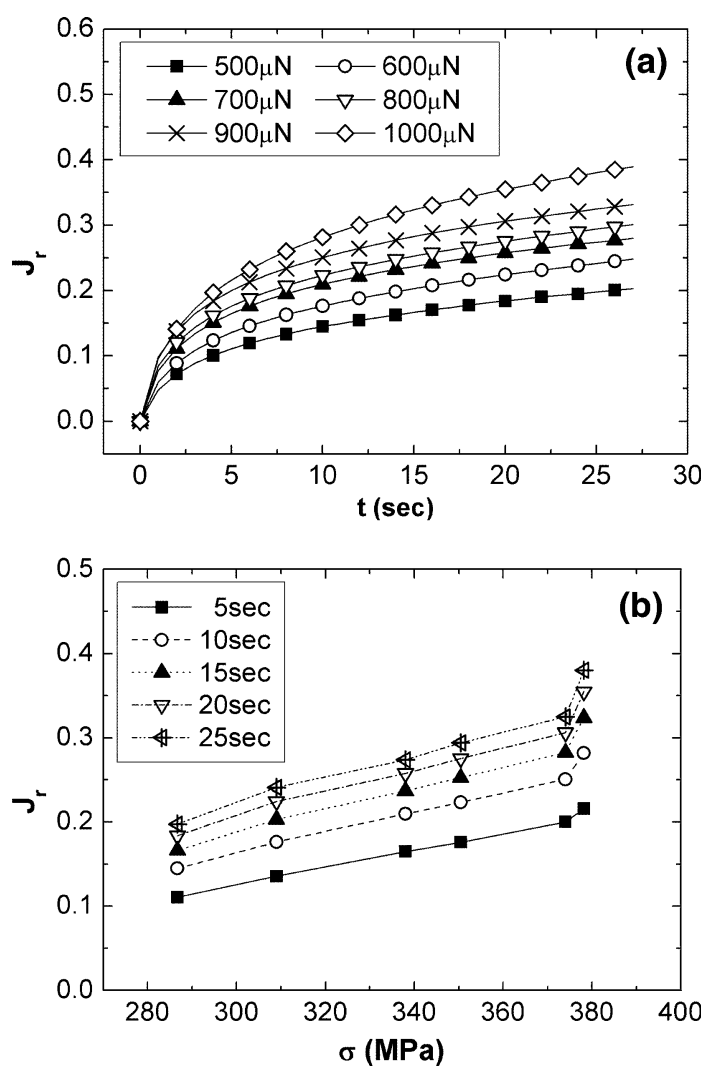
where $A$ and $n$ are constants depending on material properties and experimental conditions. The exponent number, $n$, varies between 1 and $\infty$. For a conical indenter, the creep rate and nominal stress are calculated, respectively, as (Kermouche et al. 2007),

$$
\dot{\varepsilon}(t)=\frac{1}{h} \frac{d h(t)}{d t}, \quad \sigma(t)=\frac{P_{\max }}{A_{c}(t)}
$$

The creep rate, as shown in Fig. 6a, is extremely large at the beginning of creep and then drops down very fast to a quasi-stable value, indicating the transition from the primary to stationary stage. The quasi-stable creep rate represents the most important property of materials to resist the creep deformation. The stress, as shown in Fig. 6b, shows a moderate decreasing trend with increasing time, due to the gradual increase in the contact area. However, it is worthy to note that only in the primary creep stage, the stress decreases evidently with time, while in the stationary stage, the decrease slows down. This phenomenon is always observed regardless of the level of creep load.

In this section, only stationary creep is considered which is important for longterm utilization of the material. The average values of stress and creep rate in the stationary stage (larger than $20 \mathrm{~s}$ ) were calculated for each load applied to establish

Fig. 6 Time trends of a creep rate and $\mathbf{b}$ stress in creep tests
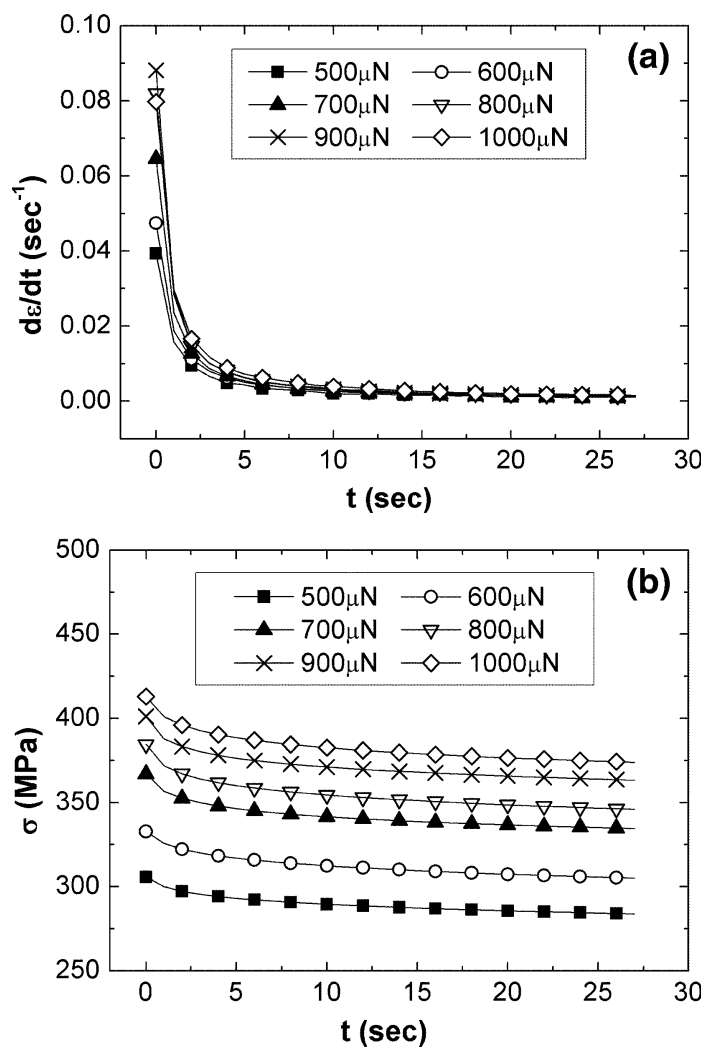
the power law relation for wood cell walls. The stress exponent number was determined to be $1.042\left(R^{2}=0.54\right)$ by linear fitting (Fig. 7). Therefore, for Cp wood, in the stress range from 280 to $380 \mathrm{MPa}$, weak but surely nonlinear relation between creep rate and stress would be concluded.

Depth dependence of dynamic properties

In nanoindentation tests, the tested properties are generally influenced by the penetration depth (Nix and Gao 1998; Fischer-Cripps 2006). Several mechanisms are proposed to account for this phenomenon, such as sample polishing, test artifacts and material properties (Bull 2003). In this study, CSM tests were conducted to check this phenomenon of penetration depth dependency for $\mathrm{Cp}$ wood cell walls.

The results are shown in Fig. 8. The reduced storage modulus, $E_{r}{ }^{\prime}$, shows a moderate decreasing trend consistent with depth because of the penetration size effect. As to the damping coefficient, $\tan \delta$, despite the wave-shape error, it shows no dependence on penetration depth. An average value of 0.03 can be concluded in the tested range. However, the fluctuation of $\tan \delta$ values decreases with increasing depth, signifying a more reliable value at deep penetration.

In the studies by Zhang et al. (2008, 2009) on epoxy and epoxy nano-composites, similar results of storage modulus and damping coefficient are obtained. However, in their studies, the storage modulus becomes gradually stable when the penetration depth is large enough. Compared with woods, the microstructures of the epoxy and epoxy nano-composites are quite homogeneous. The complicated microstructures of wood cell walls make the storage modulus to be always depth dependent. Regarding the damping coefficient, it is mainly dependent on the matrix of wood cell wall, insensible to microstructures and thus to the penetration depth.

Frequency dependence of dynamic properties

The storage modulus and loss modulus indicate, respectively, the ability of the wood constituent polymers to store energy (through recoverable deformation) and

Fig. 7 Dependence of creep rate on stress

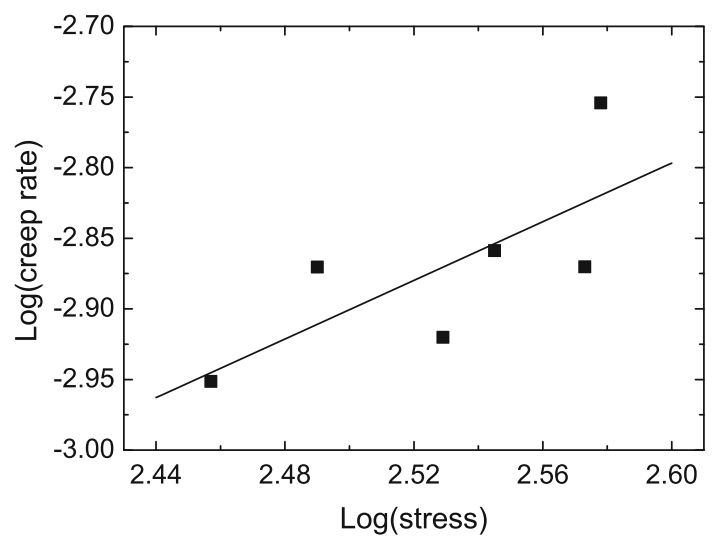


Fig. 8 Dependence on penetration depth of a the reduced storage modulus and b the damping coefficient obtained by CSM. The dark line represents the nonlinear fitting curve of the experimental data
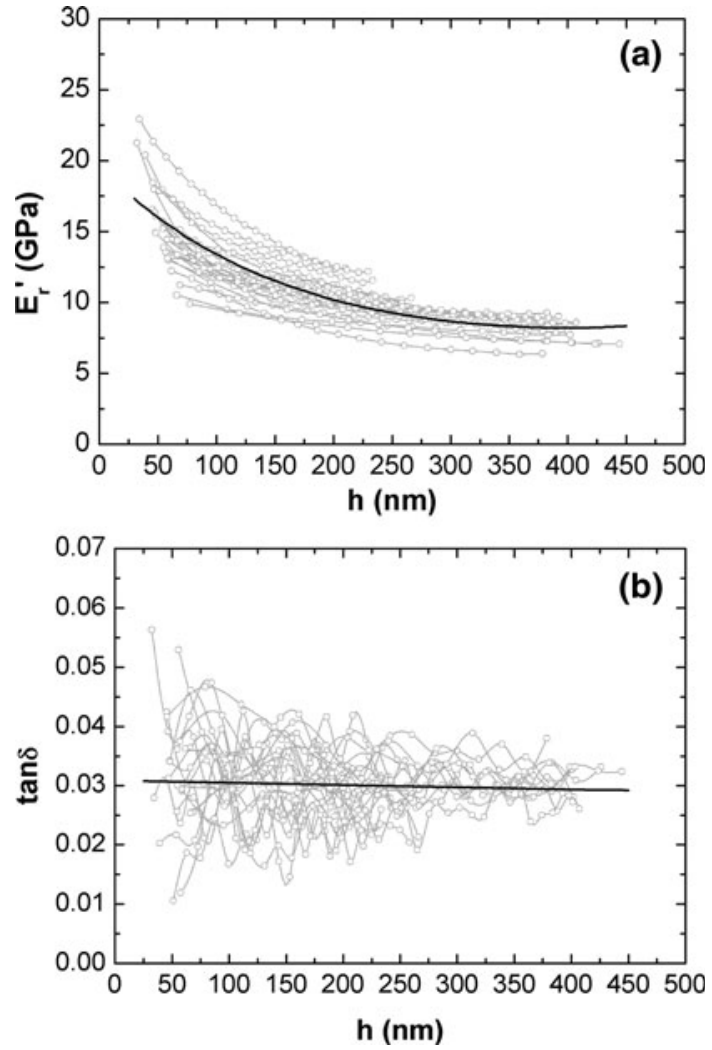

dissipate energy (through molecular chain interaction, such as internal friction and rearrangement of the chains due to deformation) (Chakravartula and Komvopoulos 2006). Their variation with frequency can be measured by Nano-DMA tests.

The test results are shown in Fig. 9, with the dark lines indicating the average values. For the storage modulus (Fig. 9a), every single test is quite stable with a fluctuation of about $5 \%$ and the continuous increasing trend with frequency is statistically significant ( $F$ test, $P<0.001$ ). However, $E_{r}^{\prime}$ values measured at 50 locations (50 tests) range from 7 to $15 \mathrm{GPa}$, so the fluctuation concerning the entire 50 tests is much larger. In this case, the fluctuation or scattering reflects the heterogeneity of wood properties due to the special cell wall structures. Despite scatter from one position to another, the dependent trend of $E_{r}^{\prime}$ on frequency (precisely the slope) is not changed. From the viewpoint of molecular chain movement, the higher the frequency is (i.e., less time available), the smaller scale molecular movements are involved. To be specific, at lower frequency, the smaller storage modulus is assigned to the relatively flexible molecular chain. While at higher frequency, main chain movements are probably frozen and small-scale movements (such as rotation around the main chain) dominant, resulting in a stiffer material (i.e., higher storage modulus). The large dispersion of the results among 50 tests reflects the heterogeneity of the wood properties due to the special cell wall 
structure on the one hand, and the position sensitivity of nanoindentation tests on the other hand.

The damping coefficient shows a quasi-linear decreasing trend with the frequency as shown in Fig. 9b, despite the large fluctuation of experimental data. In this case, each measurement has a zigzag-type variation with a fluctuation less than $20 \%$, reflecting the weak stability of measurements. However, all 50 measurements have the same phenomenon, and all experimental data are overlapped or vary in a narrow band. This is different from the data variation pattern of the reduced storage modulus. This can be explained by the fact that the damping coefficient is dominated by the matrix while the reduced storage modulus is influenced greatly by the contact area and thus by the complicated microstructure and heterogeneity of the wood surface. The general decreasing trend of $\tan \delta$ is attributed to the stiffening of the wood surface with increasing frequency because the time is shorter for molecular chain deformation and rearrangement in the vicinity of the tip. However, two transitions are revealed: a flat peak at a frequency of $30 \mathrm{~Hz}$ and a sharp peak at $210 \mathrm{~Hz}$. The increase of $\tan \delta$ is attributed to the localized softening of the amorphous phase due to the greater amount of energy dissipated in the near-surface region. The dissipation energy would increase the free volume in this region and promote the chain mobility, therefore, resulting in a more

Fig. 9 Dependence on frequency of a reduced storage modulus; b damping coefficient obtained by Nano-DMA. The dark line represents the average value
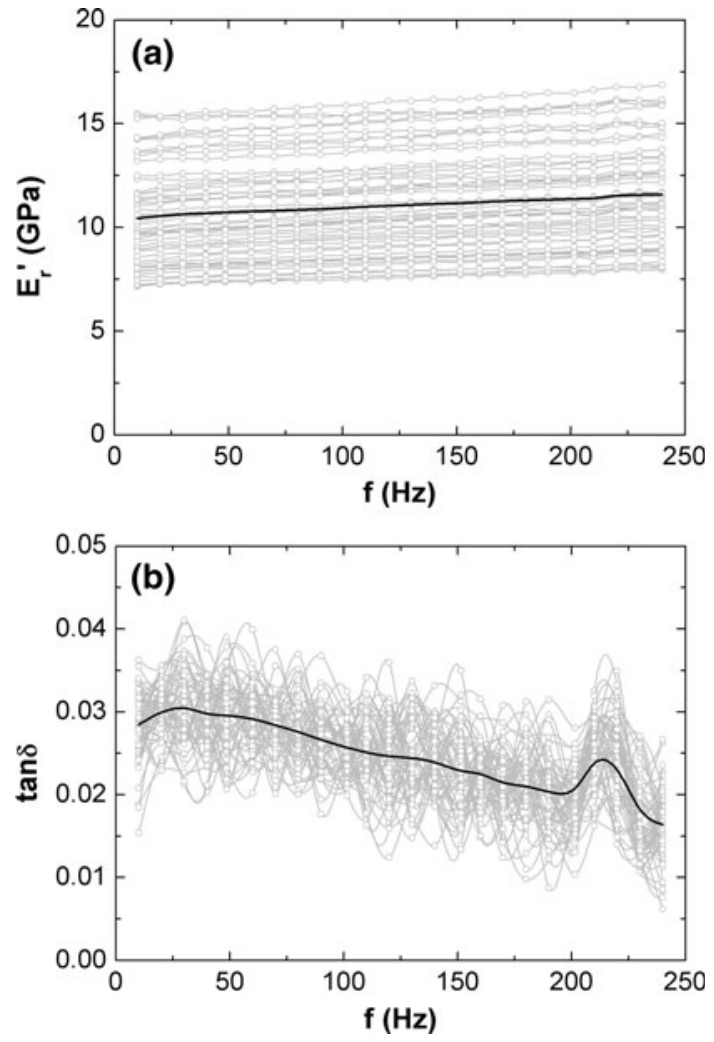
viscous behavior. This enhancement of viscous behavior saturates at a critical frequency and then, because of the stiffening of the molecular configuration, $\tan \delta$ begins to decrease (Chakravartula and Komvopoulos 2006; Zhang et al. 2008).

The Nano-DMA method gives the evolution of dynamic properties with variant frequency under a constant temperature, which is different from the dynamic thermal mechanical analysis (DMTA) method. For the later, the dynamic properties of bulk wood specimens are obtained with temperature variation at a constant frequency. What is the relationship between these two methods?

It is well known that for polymers and polymer composites, the time-temperature equivalence principle is valid and successfully used to predict the long-term behavior of materials by studying it under a wide temperature range. Because the frequency is a time concept, it is possible to extend the time-temperature equivalence principle to frequency-temperature equivalence principle. In such a way, it is possible to establish the relationship between traditional DMTA method and Nano-DMA method. This view point inspires to carry out, as a complementary study, DMTA tests and to compare the dynamic behaviors obtained with two different methods.

The DMTA tests were undertaken with a dynamic mechanical analyzer (DMA2980, TA Instrument) using a specimen prepared from approximately the same section as the Nano-DMA specimen with a geometry of $35 \times 10 \times 3 \mathrm{~mm}^{3}$ $(\mathrm{L} \times \mathrm{T} \times \mathrm{R})$. The tests were conducted at a frequency of $1 \mathrm{~Hz}$ and a temperature range of -120 to $250^{\circ} \mathrm{C}$. Four measurements were performed to confirm the resulting curve, shown in Fig. 10.

The dynamic behavior of wood materials with temperature variation is complicated compared with those of man-made homogeneous polymers, due to the coupling of thermal properties of three constituent polymers. This point is made clear by the $\tan \delta$ curve which has several peaks. The relaxation process at about $-90^{\circ} \mathrm{C}$ is attributed to the motions of methyl groups in the amorphous region of the wood cell wall and the motions of absorbed water molecules in wood. The relaxation process at around $250^{\circ} \mathrm{C}$ is assigned to the micro-Brownian motion of cell wall polymers in the noncrystalline region (Sugiyama and Norimoto 1996; Sugiyama et al. 1998). The transition at $25^{\circ} \mathrm{C}$ is probably related to the glass transition of hemicelluloses with low molecular weight and also the molecular

Fig. 10 Temperature evolution of storage modulus and damping coefficient of Carapa procera wood obtained by DMTA tests

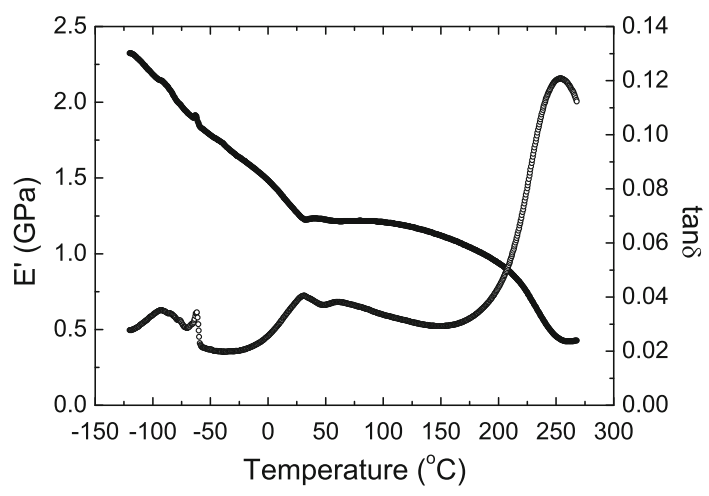


motion of lignin (Furuta et al. 2000; Obataya et al. 2000). A sharp peak at around $-60^{\circ} \mathrm{C}$ is repeatedly observed in the tests here and has not been reported by other researchers. It is supposed to relate to the existence of water molecular and extractives with small molecular weight.

By comparing Fig. 9b with Fig. 10, for Nano-DMA tests, the flat peak at about $30 \mathrm{~Hz}$ and the sharp peak at around $210 \mathrm{~Hz}$ of damping coefficient are considered to correspond to the transition at $25^{\circ} \mathrm{C}$ and $-60^{\circ} \mathrm{C}$ for DMTA tests, respectively. Therefore, with the Nano-DMA method, the phase transitions of wood viscoelastic behavior can be characterized just as well as with traditional DMTA method, but in a more rapid process. A remarkable advantage of Nano-DMA tests is that it permits to reveal the viscoelastic behavior of woods in a wide frequency range, instead of only temperature change.

\section{Conclusion}

The viscoelastic properties of the cell wall of the tropic hardwood Carapa procera are successfully investigated by using three types of nanoindentation tests, that is, creep, continuous stiffness method (CSM) and nanoscale dynamic mechanical analysis (Nano-DMA). The behavior of creep follows the rule of power law, while the creep rate depends on the applied stress level. The stress index near unity signifies the quasi-linear viscoelastic behavior of the tropic hardwood Carapa procera. It is found from the dynamic tests that the storage modulus and damping coefficient are strongly dependent on both penetration depth and loading rate (i.e., oscillation frequency). The peak of damping coefficient on the frequency spectrum permits to know, for the first time, the phase transition behavior of woods by nanoindentation tests. This is confirmed by the dynamic thermal mechanical analysis (DMTA) on the bulk Carapa procera wood specimens. The dispersion of the results reflects the properties variation due to the microstructural inhomogeneity of woods. However, the average values of the above properties are representative and reliable, which also proves the nanoindentation to be valuable and powerful in determining the local properties of wood materials.

\section{References}

Asif SAS, Wahl KJ, Colton RJ (1999) Nanoindentation and contact stiffness measurement using force modulation with a capacitive load-displacement transducer. Rev Sci Instrum 70(5):2408-2413

Bower AF, Fleck NA, Needleman A, Ogbonna N (1993) Indentation of a power law creeping solid. Proc Math Phys Sci 441(1911):97-124

Bull SJ (2003) On the origins and mechanisms of the indentation size effect. Z Metallkd 94(7):787-792 Chakravartula A, Komvopoulos K (2006) Viscoelastic properties of polymer surfaces investigated by nanoscale dynamic mechanical analysis. Appl Phys Lett 88:131901

Cheng L, Xia X, Yu W, Scriven LE, Gerberich WW (2000) Flat-punch indentation of viscoelastic material. J Polym Sci Part B 38:10-22

Fischer-Cripps AC (2006) Review of analysis and interpretation of nanoindentation test data. Surf Coat Tech 200(14-15):4153-4165 
Furuta Y, Imanishi H, Kohara M, Yokoyama M, Obata Y, Kanayama K (2000) Thermal-softening properties of water-swollen wood (vii) the effects of lignin. Mokuzai Gakkaishi 46(2):133-137

Gindl W, Gupta HS, Schoberl T, Lichtenegger HC, Fratzl P (2004) Mechanical properties of spruce wood cell walls by nanoindentation. Appl Phys A 79(8):2069-2073

Guitard D (1983) The wood materials: properties, technology, processing. Collection of lessons exempted during winter school on woods in Albe (68) from 24 to 29 January 1983, Association for the research on woods in Loraine (Association pour la Recherche sur le Bois en Lorraine (ARBOLOR)), p B1-94

Isaksson H, Nagao S, Malkiewicz M, Julkunen P, Nowak R, Jurvelin JS (2010) Precision of nanoindentation protocols for measurement of viscoelasticity in cortical and trabecular bone. J Biomech 43(12):2410-2417

Kermouche G, Loubet JL, Bergheau JM (2007) Cone indentation of time-dependent materials: the effects of the indentation strain rate. Mech Mater 39(1):24-38

Konnerth J, Gierlinger N, Keckes J, Gindl W (2009) Actual versus apparent within cell wall variability of nanoindentation results from wood cell walls related to cellulose microfibril angle. J Mater Sci 44(16):4399-4406

Lee SH, Wang SQ, Pharr GM (2006) Time-dependent nano-mechanical properties of regenerated cellulose fiber and wood cell wall by continuous nanoindentation technique. Abstracts of Papers of the American Chemical Society, p 231

Liu T (1993) Creep of wood under a large-span of loads in constant and varying environments. Part 1. Experimental-observations and analysis. Holz Roh Werkst 51(6):400-405

Lu H, Wang B, Ma J, Huang G, Viswanathan H (2003) Measurement of creep compliance of solid polymers by nanoindentation. Mech Time-Depend Mater 7(3-4):189-207

Nix WD, Gao HJ (1998) Indentation size effects in crystalline materials: a law for strain gradient plasticity. J Mech Phys Solids 46(3):411-425

Obataya E, Ono T, Norimoto M (2000) Vibrational properties of wood along the grain. J Mater Sci 35(12):2993-3001

Oliver WC, Pharr GM (1992) An improved technique for determining hardness and elastic modulus using load and displacement sensing indentation experiments. J Mater Res 7(6):1564-1583

Saheb DN, Jog JP (1999) Natural fiber polymer composites: a review. Adv Polym Tech 18(4):351-363

Sugiyama M, Norimoto M (1996) Temperature dependence of dynamic viscoelasticities of chemically treated woods. Mokuzai Gakkaishi 42(11):1049-1056

Sugiyama M, Obataya E, Norimoto M (1998) Viscoelastic properties of the matrix substance of chemically treated wood. J Mater Sci 33(14):3505-3510

Tweedie CA, Van Vliet KJ (2006) Contact creep compliance of viscoelastic materials via nanoindentation. J Mater Res 21(6):1576-1589

Tze WTY, Wang S, Rials TG, Pharr GM, Kelley SS (2007) Nanoindentation of wood cell walls: continuous stiffness and hardness measurements. Compos Part A Appl Sci Manuf 38(3):945-953

VanLandingham MR, Villarrubia JS, Guthrie WF, Meyers GF (2001) Nanoindentation of polymers: an overview. Macromol Symp 167:15-43

VanLandingham MR, Chang NK, Drzal PL, White CC, Chang SH (2005) Viscoelastic characterization of polymers using instrumented indentation. I. Quasi-static testing. J Polym Sci B Polym Phys 43(14):1794-1811

White CC, Vanlandingham MR, Drzal PL, Chang NK, Chang SH (2005) Viscoelastic characterization of polymers using instrumented indentation. II. Dynamic testing. J Polym Sci B Polym Phys 43(14):1812-1824

Wimmer R, Lucas BN, Tsui TY, Oliver WC (1997) Longitudinal hardness and young's modulus of spruce tracheid secondary walls using nanoindentation technique. Wood Sci Technol 31(2):131-141

Zhang YF, Bai SL, Yang DY, Zhang Z, Kao-Walter S (2008) Study on the viscoelastic properties of the epoxy surface by means of nanodynamic mechanical analysis. J Polym Sci B Polym Phys 46(3):281-288

Zhang YF, Bai SL, Li XK, Zhang Z (2009) Viscoelastic properties of nanosilica-filled epoxy composites investigated by dynamic nanoindentation. J Polym Sci B Polym Phys 47(10):1030-1038 